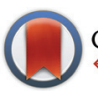

CrossMark

Cite this: Polym. Chem., 2016, 7, 451

\title{
Controlled radical polymerization and in-depth mass-spectrometric characterization of poly(ionic liquid)s and their photopatterning on surfaces $\uparrow$
}

\author{
Jan Steinkoenig, ${ }^{a, b}$ Fabian R. Bloesser, ${ }^{a, b}$ Birgit Huber, ${ }^{c}$ Alexander Welle, ${ }^{a, b}$ \\ Vanessa Trouillet, ${ }^{d}$ Steffen M. Weidner, ${ }^{e}$ Leonie Barner, ${ }^{c}$ Peter W. Roesky, ${ }^{f}$ \\ Jiayin Yuan, ${ }^{* g}$ Anja S. Goldmann*a,b and Christopher Barner-Kowollik*a,b,c
}

The preparation and characterization of poly(ionic liquid)s (PILs) bearing a polystyrene backbone via reversible addition fragmentation chain transfer (RAFT) polymerization and their photolithographic patterning on silicon wafers is reported. The controlled radical polymerization of the styrenic ionic liquid (IL) monomers ([BVBIM]X, $\mathrm{X}=\mathrm{Cl}^{-}$or $\mathrm{Tf}_{2} \mathrm{~N}^{-}$) by RAFT polymerization is investigated in detail. We provide a general synthetic tool to access this class of PILs with controlled molecular weight and relatively narrow molecular weight distribution (2000 $\mathrm{g} \mathrm{mol}^{-1} \leq M_{\mathrm{n}} \leq 10000 \mathrm{~g} \mathrm{~mol}^{-1}$ with dispersities between 1.4 and 1.3 for $\mathrm{p}([\mathrm{BVB} \mid \mathrm{M}] \mathrm{Cl}) ; 2100 \mathrm{~g} \mathrm{~mol}^{-1} \leq M_{\mathrm{P}} \leq 14000 \mathrm{~g} \mathrm{~mol}^{-1}$ for $\mathrm{p}\left([\mathrm{BV} \mathrm{BIM}] T \mathrm{Tf}_{2} \mathrm{~N}\right)$ ). More importantly, we provide an in-depth characterization of the PILs and demonstrate a detailed mass spectrometric analysis via matrix-assisted laser desorption ionization (MALDI) as well as - for the first time for PILs - electrospray ionization mass spectrometry (ESI-MS). Importantly, $\mathrm{p}([\mathrm{BVB} \mid \mathrm{M}] \mathrm{Cl})$ and $\mathrm{p}\left([\mathrm{DMVB} \mid \mathrm{M}] \mathrm{Tf}_{2} \mathrm{~N}\right)$ were photochemically patterned on silicon wafers. Therefore, a RAFT agent carrying a photoactive group based on ortho-quinodimethane chemistry - more precisely photoenol chemistry - was photochemically linked for subsequent controlled radical polymerization of $[\mathrm{BVBIM}] \mathrm{Cl}$ and $[\mathrm{DMVBIM}] \mathrm{Tf}_{2} \mathrm{~N}$. The successful spatially-resolved photografting is evidenced by surface-sensitive characterization methods such as X-ray photoelectron spectroscopy (XPS) and time-of-flight secondary ion mass spectrometry (ToF-SIMS). The presented method allows for the functionalization of diverse surfaces with poly(ionic liquid)s.

Received 19th August 2015, Accepted 22nd October 2015 DOI: $10.1039 / \mathrm{c} 5$ py01320h www.rsc.org/polymers

\section{Introduction}

Ionic liquids (ILs) are organic salts with a melting point typically below $100{ }^{\circ} \mathrm{C}$. They have found significant applications in various fields ranging from chemistry to physics and materials science. ${ }^{1}$ Recently, the polymerization of ILs, which forms a new class of ionic polymers, so called poly(ionic liquid)s (PILs), has emerged as a multifunctional platform that combines the advantages of ILs with the general property profile of polymers. ${ }^{2-6}$ PILs are not only a natural extension of properties and function of ILs in materials science, but significantly advance the research scope of ionic polymers. For example, in spite of a high ion-pair packing density, the favorable solubility in a broad range of organic solvents and the achievable low glass transition temperature of structurally well-defined PILs offer new processing possibilities to fabricate ionic polymers for numerous functional materials.

Currently, the chemical structure of polymerizable ILs is dominated by the imidazolium type, which can be further classified into three major subgroups, i.e. the vinylimidazolium, (meth)acrylate, and styrenic ones. In the past several 
years, a wide range of polymerization techniques have been exploited to synthesize imidazolium-type PILs with defined structure characteristics. Among them, reversible deactivation radical polymerization techniques, such as the atom transfer radical polymerization (ATRP), and reversible addition-fragmentation chain-transfer (RAFT) polymerization are frequently used. $^{7-12}$ These radical polymerization techniques allow for superior control over the polymer chain characteristics and the endgroup functionalization.

PILs bearing styrenic type IL monomer units have a rigid polystyrene backbone that can provide mechanical stability to lock the highly ionic polymer matrix. These PILs are promising candidates as support for IL networks. For example, covalent porous IL networks are often generated from styrenic type IL monomers. ${ }^{13}$ Additionally, PIL membrane materials for gas separation or sorption take advantage of the rigid polystyrene backbone to enhance the shape durability of membranes and the gas flux rate. ${ }^{14}$ Preparation of such PILs from styrenic IL monomers is a synthetic task that usually involves free radical polymerization, which is easy to implement and important for large scale production. Yet, to understand the intrinsic structure-property-function relationship for further optimization of their materials performance, PILs with defined chain length and narrow molecular weight distribution are absolutely necessary. In literature, ATRP of a styrenic IL monomer has been reported by the groups of Matyjaszewski and Gin. ${ }^{8,15}$ Both groups demonstrated that via ATRP, the PIL chain characteristics are tuneable and their block copolymers are accessible. An inherent problem in the polymerization of IL monomers by ATRP is, however, the inevitable ion exchange process between the required metal catalyst, copper halide and the IL monomer. Further, $\mathrm{Cu}$ ions may form complex anions with certain IL anions, ${ }^{16}$ which makes it even more challenging to be removed from the polymer product. Therefore, in spite of excellent control over the polymerization process via ATRP, the field is motivated to search for alternative polymerization techniques to overcome these challenges. One solution is to apply RAFT polymerization that generally involves no metal salt. A study by Tenhu and coworkers ${ }^{17}$ reported briefly that it is possible to polymerize a specific styrenic type chiral IL monomer, yet the RAFT polymerization of more representative and commonly used styrenic IL monomers, such as 1-butyl-3-( $p$-vinylbenzyl)-imidazolium-based IL monomers was not presented. Recently, Detrembleur and coworkers ${ }^{18}$ demonstrated the preparation of vinylimidazolium-based block PILs featuring two different counter ions via RAFT polymerization.

The precise characterization of PIL chain features, in general, is very challenging. Due to the strong interactions with the column materials, size exclusion chromatography results in broadened traces, or in a complete absorption on the column surface. Different teams pioneered measuring PILs with different counter ions by SEC. ${ }^{19,20}$ However, to date, only little efforts towards the detailed mass spectrometric analysis of these materials have successfully been carried out. ${ }^{8,9,21}$ Motivated by the current status, we initiated the project on
RAFT polymerization of frequently used styrenic IL monomers and provide a general synthetic protocol to access these PILs with controlled molecular weight, narrow molecular weight distribution, defined chain endgroup and no contamination from metal ion species. More precisely, we investigate the controlled radical polymerization of 1-butyl-3-( $p$-vinylbenzyl $)-1 H^{-}$ imidazolium chloride ([BVBIM]Cl, (1)) and 1-butyl-3-( $p$-vinylbenzyl)-1 $H$-imidazol-3-ium bis(trifluoromethanesulfonyl)imide ([BVBIM]Tf $\left.{ }_{2} \mathrm{~N},(2)\right)$ (Scheme 1) via RAFT polymerization and provide a comprehensive characterization of the polymers by various (mass spectrometric) analysis methods such as SEC, MALDI-ToF MS as well as ESI-MS. To the best of our knowledge, the mass spectrometric characterization via ESI-MS is shown for the first time in-depth.

In addition, surface design is a rapidly growing field in contemporary chemistry. PIL-decorated surfaces can serve as imaging, wetting/dewetting, and anti-biofouling interfaces. ${ }^{8,22,23}$ Initiated by the pioneering work of Ye et al. on grafted PILs via ROMP on $\mathrm{TiO}_{2}$ substrates and the positive anti-fouling studies, ${ }^{23}$ Matyjazewski and coworkers thermally attached well-characterized, ATRP-prepared PILs on Si substrates that potentially could show anti-fouling characteristics. ${ }^{8}$ Furthermore, Drockenmueller and coworkers patterned azidefunctionalized copolymerized PILs via UV irradiation and subsequent formation of highly reactive nitrenes on a silicon substrate. ${ }^{24}$ Herein, we present a polymerization study of $\mathrm{p}([\mathrm{BVBIM}] \mathrm{Cl})$ and $\mathrm{p}\left([\mathrm{BVBIM}] \mathrm{Tf}_{2} \mathrm{~N}\right)$ in order to investigate the mass spectrometric behavior of PILs in solution. Furthermore, we study the characterization of photochemically patterned $\mathrm{p}([\mathrm{BVBIM}] \mathrm{Cl})$ and $\mathrm{p}[1,2$-dimethyl-3-( $p$-vinylbenzyl)- $1 H$-imidazol-3-ium bis(trifluoro methanesulfonyl)imide] (p([DMVIM]$\left.\mathrm{Tf}_{2} \mathrm{~N}\right)$ ) via a surface sensitive mass spectrometric analytical method, i.e. time-of-flight secondary ion mass spectrometry (ToF-SIMS) as well as X-ray photoelectron spectroscopy (XPS).

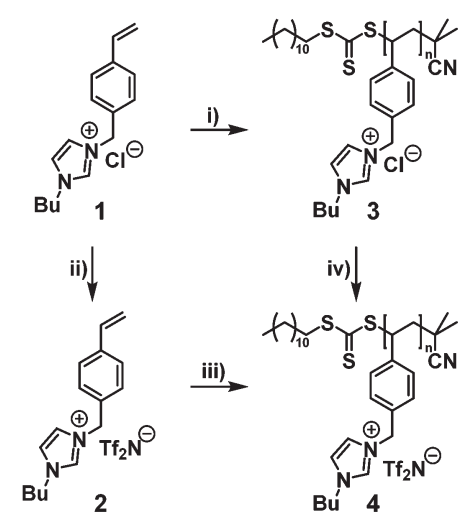

Scheme 1 Synthetic approach for the preparation of $p([B V B I M] C l)(3)$ and $p\left([B V B I M] T f_{2} N\right)(4)$ from the monomers [BVBIM]Cl (1) and $[B V B I M] T f_{2} N$ (2), respectively. Molar ratio $[M]:[C T A]$ : [l] for (i) $200: 1: 0.2$ and for (iii) $200: 1: 0.2$ (i: RAFT polymerization; ii: $\mathrm{Tf}_{2} \mathrm{~N}^{-}$vs. $\mathrm{Cl}^{-}$anion exchange; iii: RAFT polymerization; iv: anion exchange). 


\section{Results and discussion}

Among other versatile features of the RAFT process, ${ }^{25}$ the high tolerance towards functional monomers e.g. acrylic acids or vinyl esters, is an important characteristic. It is also expected to be a suitable candidate for the controlled radical polymerization of monomeric ILs and thus applied in the presented work. Scheme 1 summarizes the synthetic strategy for the preparation of the polymers $\mathrm{p}([\mathrm{BVBIM}] \mathrm{Cl})(3)$ and $\mathrm{p}\left([\mathrm{BVBIM}] \mathrm{Tf}_{2} \mathrm{~N}\right)$ (4). It should be noted that the synthesis and properties of 1-alkyl-3-( $p$-vinylbenzyl)-imidazolium based PILs was widely investigated, ${ }^{8,15,26}$ yet the RAFT process of the corresponding monomers remains a challenge.

The polymerization of these ILs can either be achieved by the direct polymerization of $[\mathrm{BVBIM}] \mathrm{Tf}_{2} \mathrm{~N}$ (2) or by the polymerization of [BVBIM]Cl (1) followed by a counter ion exchange with $\mathrm{Tf}_{2} \mathrm{~N}^{-}$. Both monomers [BVBIM]Cl (1) and [BVBIM] $\mathrm{Tf}_{2} \mathrm{~N}(2)$ were synthesized by a quaternization reaction between 4 -vinylbenzyl chloride and $n$-butylimidazole with a slightly modified synthesis protocol given in the literature. ${ }^{27}$ A counter ion exchange with $\mathrm{Tf}_{2} \mathrm{~N}^{-}$resulted in 2 . The polymerization of [BVBIM]Cl (1) was performed in DMSO as solvent of choice ensuring a good dissolution of both the IL monomer (1) and 2-cyano-2-propyl dodecyl trithiocarbonate (CPDT) as chain transfer agent (CTA). A molar ratio of the reagents $[\mathrm{M}]:[\mathrm{CTA}]:[\mathrm{I}]=200: 1: 0.2$ (Initiator: 1,1'-azobis(cyclohexanecarbonitrile)) was used. Interestingly, the RAFT polymerization of [BVBIM]Cl (1) is highly affected by the choice of the solvent. For instance, protic solvents, such as ethanol, methanol and water, led to a less controlled polymerization (refer to Table S1 in the ESI $\dagger$ ). The polymerization of [BVBIM] $\mathrm{Tf}_{2} \mathrm{~N}(2)$ was performed in butyronitrile as solvent due to its favorable solubility in non-polar/aprotic solvents. In general, the common controlled polymerization techniques, i.e. ATRP, RAFT and NMP, are complex and challenging for IL monomers such as 1 and 2 because of their ionic character. ${ }^{20}$ The RAFT polymerization of $[\mathrm{BVBIM}] \mathrm{Cl}$ (1) was carried out employing CPDT as chain transfer agent in DMSO at $85{ }^{\circ} \mathrm{C}$ and VAZO- $88\left(k_{\mathrm{d}}=2.01 \times 10^{5} \mathrm{~s}^{-1}\right)^{28}$ as radical starter. The molecular weight evolution of the SEC traces in Fig. 1(A) verifies the living character. Both the ${ }^{1} \mathrm{H}$ NMR (Fig. S11†) as well as the SEC results are in good agreement with the theoretically obtained molecular weights (Fig. 1(B): solid line). $\mathrm{P}([\mathrm{BVBIM}] \mathrm{Cl})(3)$ is a charged polymer and thus interacts strongly with the column material and its polymer chains via hydrogen bonding of the chloride counter ion. As a consequence, halide-containing PILs prepared via RAFT polymerization often display a rather broad dispersity in a $\mathrm{H}_{2} \mathrm{O}-\mathrm{SEC}$ system. ${ }^{9}$

Thus, the optimum system for the SEC analysis has to be identified to suppress the intermolecular polymer and column interactions. In order to investigate the most appropriate eluent, the SEC measurements were carried out by variation of the polymer concentrations (in $\mathrm{mg} \mathrm{mL}^{-1}$ ) as well as sodium chloride salt concentrations (refer to Fig. S1 $\dagger$ ). The $\mathrm{H}_{2} \mathrm{O}-\mathrm{SEC}$ system with a water/0.3 $\mathrm{M}$ formic acid/0.5 $\mathrm{g} \mathrm{L}^{-1} \mathrm{NaCl}$ mixture as eluent was identified as ideal system for the polymeric
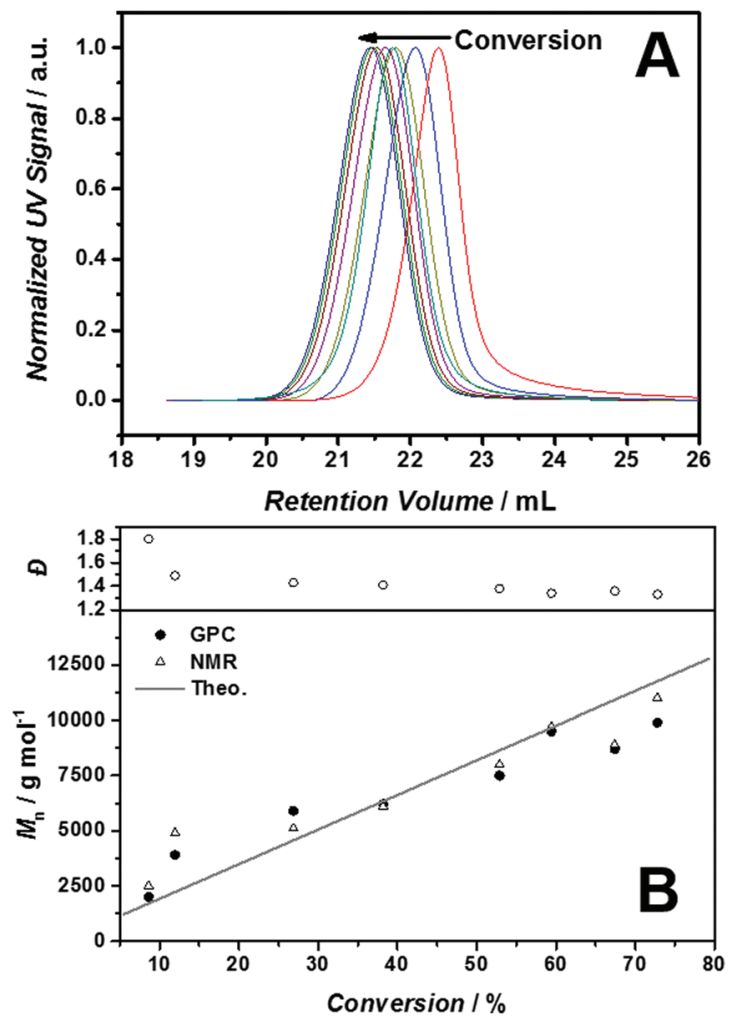

Fig. 1 (A) SEC traces of $\mathrm{p}([\mathrm{BVBIM}] \mathrm{Cl})$ (3) via the RAFT mediated polymerization of [BVBIM]Cl (1) at $85^{\circ} \mathrm{C}$ in DMSO. (B) Plot of molecular weight $\left(M_{n}\right)$ and dispersity $(\Theta)$ vs. monomer conversion. Molar ratio of monomer: CTA : initiator $200: 1: 0.2$ (CTA = 2-cyano-2-propyl dodecyl trithiocarbonate; initiator $=1,1^{\prime}$-azobis(cyclohexanecarbonitrile)). $\mathrm{H}_{2} \mathrm{O}-$ SEC system conditions: water/0.3 $\mathrm{M}$ formic acid $/ 0.5 \mathrm{~g} \mathrm{~L}^{-1} \mathrm{NaCl}, 30^{\circ} \mathrm{C}$, flow rate $1.0 \mathrm{~mL} \mathrm{~min}{ }^{-1}$.

system (3). The system was calibrated against poly(4-vinylpyridine), which forms a polycation under SEC conditions and thus allows for a more accurate estimation of the molecular weight of our PILs. Furthermore, we have demonstrated that the dispersity decreases after successful salt metathesis of the corresponding $\mathrm{p}([\mathrm{BVBIM}] \mathrm{Cl})(3)\left(M_{\mathrm{n}}=8900 \mathrm{~g}\right.$ $\left.\mathrm{mol}^{-1} ; D=1.55 ; \mathrm{DP}_{\mathrm{n}}=37\right)$ against $\operatorname{LiTf}_{2} \mathrm{~N}$ resulting in $\mathrm{p}\left([\mathrm{BVBIM}] \mathrm{Tf}_{2} \mathrm{~N}\right)(4)$ with a dispersity of 1.2 (SEC analysis with an eluent containing $10 \mathrm{mM} \mathrm{LiTF}_{2} \mathrm{~N}$ and $10 \mathrm{mM} n$-butylimidazole). The calibration against polystyrene was in good agreement to the results obtained with the $\mathrm{H}_{2} \mathrm{O}-\mathrm{SEC}$ system (refer to Fig. S1†).

The polymerization of the $\mathrm{Tf}_{2} \mathrm{~N}^{-}$containing monomeric IL 2 can be achieved in a similar synthetic approach. CPDT was used as chain transfer agent in butyronitrile at $85{ }^{\circ} \mathrm{C}$ and $1,1^{\prime}$-azobiscyclohexane-carbonitrile as initiator.

Fig. 2(A) shows the molecular weight evolution for the RAFT polymerization of [BVBIM] $\mathrm{Tf}_{2} \mathrm{~N}(4)\left(10 \mathrm{mmol} \mathrm{LiTf}_{2} \mathrm{~N}, 10 \mathrm{mmol}\right.$

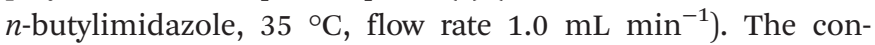
trolled molecular weight evolution is depicted in Fig. 2(B). The determination of molecular weights of the polymers $\left(M_{\mathrm{n}}<\right.$ $10000 \mathrm{~g} \mathrm{~mol}^{-1}$ ) is hampered by the presence of residual 

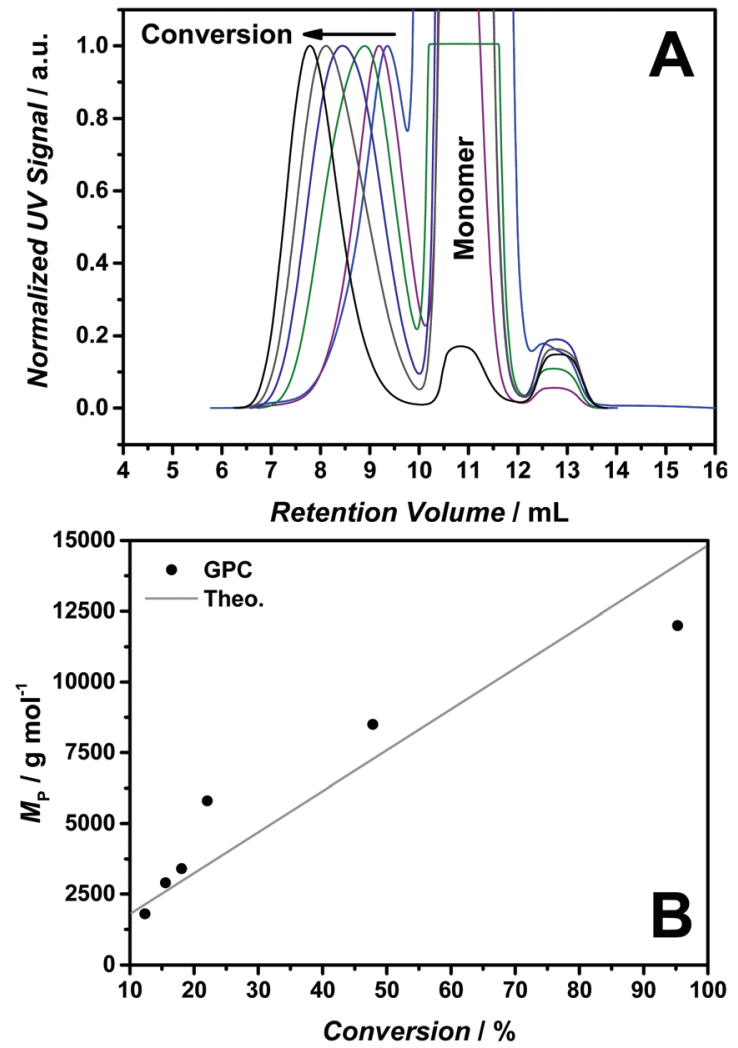

Fig. 2 (A) Molecular weight evolution of the RAFT polymerization of [BVBIM] $T f_{2} \mathrm{~N}$ (2) at $85{ }^{\circ} \mathrm{C}$ in butyronitrile. (B) Molecular weight evolution $\left(M_{P}\right)$ with conversion for the RAFT mediated polymerization of 2. Molar ratio $[\mathrm{M}]:[\mathrm{CTA}]:[\mathrm{l}]=200: 1: 0.2,85^{\circ} \mathrm{C}$, butyronitrile (CTA: 2-cyano-2propyl dodecyl trithiocarbonate; I = 1,1'-azobiscyclohexane carbonitrile). THF-SEC system conditions: $10 \mathrm{mmol}^{\mathrm{LiTf}} \mathrm{N}_{2} \mathrm{~N}, 10 \mathrm{mmol} n$-butylimida-

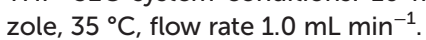

monomer. Precipitation in methanol/water was not successful, also dialysis in water ( $3 \mathrm{~d}$ at ambient temperature as well as for $14 \mathrm{~d}$ at elevated temperatures of close to $40{ }^{\circ} \mathrm{C}$ ) did not result in pure PILs. The dialysis in THF or acetone according to a literature method $^{8}$ may work for high-molecular weight PILs, however failed for our low-molecular weight polymers (due to diffusion out of the membrane). The dialysis in DMSO was successful for certain polymer samples, however, we were not able to implement the DMSO purification as a standard dialysis for $\mathrm{Tf}_{2} \mathrm{~N}^{-}$containing PILs. Thus, the polymer signals and the monomer signal overlap in the SEC trace. The overlap is most likely due to the SEC column system in our laboratory that differs slightly from the SEC column system employed by Matyjaszewski and coworkers. ${ }^{8,20}$

Thus, the peak of the molecular weight $\left(M_{\mathrm{P}}\right)$ was correlated with the conversion indicating a linear trend. However, the dispersity $(\nexists)$ (due to the overlap of the polymer signal and the monomer signal) was not determined and also the $M_{\mathrm{n}}$ determination via NMR spectroscopy was hampered by the presence of the residual monomer.

Table 1 provides an overview of the molecular weights calculated according to the monomer conversion, as well as the molecular weights obtained by NMR spectroscopy and SEC for 3 and 4. Salt exchange against bis(trifluoromethanesulfonyl)imide $\left(\mathrm{Tf}_{2} \mathrm{~N}^{-}\right)$converts the water-soluble polymers into highly hydrophobic ones that are soluble in solvents such as THF, DMAc and acetone. ${ }^{29}$ Matyjaszewski and co-workers have shown that such PILs can easily be characterized by SEC with THF as eluent containing a small concentration of the appropriate counter ion. ${ }^{20}$

In contrast to SEC, mass spectrometry is often employed in order to characterize the polymer chain structure. Nevertheless, mass spectrometric analysis of PILs is a considerable challenge because of their ionic character. ${ }^{4}$ In particular when endgroup analysis is required, the determination of the exact mass is a crucial step for a detailed characterization of the synthesized materials, i.e. for subsequent post-modification reactions. ${ }^{30}$ Electrospray ionization mass spectrometry (ESI-MS) ${ }^{31}$ and matrix assisted laser desorption ionization (MALDI) ${ }^{32}$ are the methods of choice for an in-depth characterization of the

Table 1 Characterization of $\mathrm{p}([\mathrm{BVBIM}] \mathrm{Cl})(3)$ and $\mathrm{p}\left([\mathrm{BVBIM}] \mathrm{Tf} \mathrm{f}_{2} \mathrm{~N}\right)(4)$ prepared by RAFT polymerization in different solvents. Conditions for 3 : $85^{\circ} \mathrm{C}$, CPDT, VAZO-88, [M] : [CTA] : [I] = $200: 1: 0.2$, DMSO. Conditions for $4: 85^{\circ} \mathrm{C}, \mathrm{CPDT}$, VAZO-88, [M] : [CTA] : [I] = $200: 1: 0.2$, butyronitrile

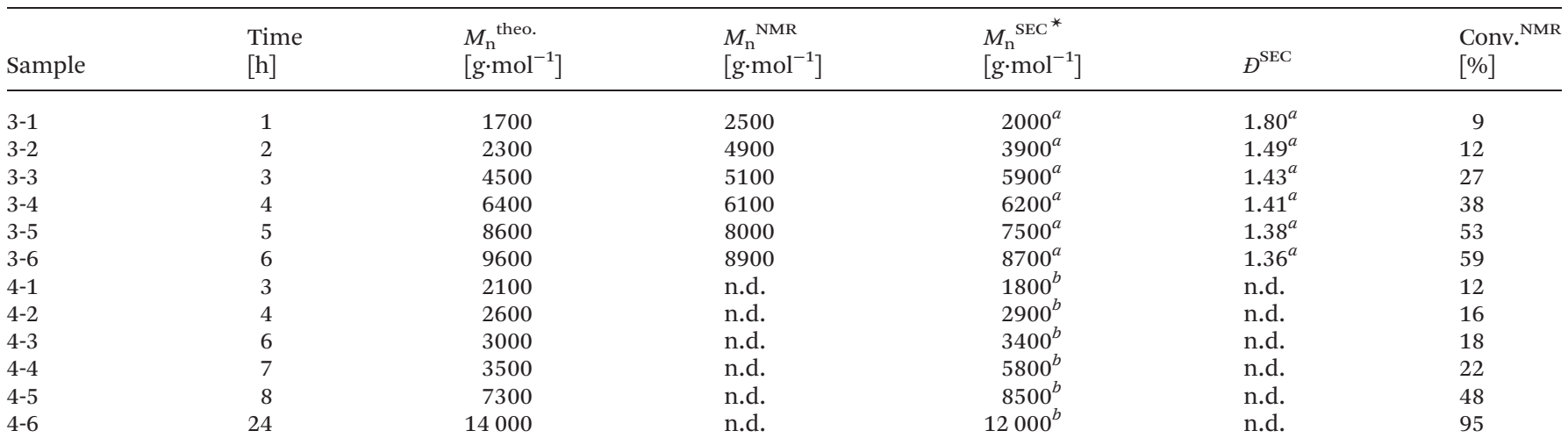

${ }^{*}$ For samples 3: $M_{\mathrm{n}}{ }^{\mathrm{SEC}}\left[\mathrm{g} \mathrm{mol}^{-1}\right]$; for samples 4: $\mathrm{M}_{\mathrm{p}}{ }^{\mathrm{SEC}}\left[\mathrm{g} \mathrm{mol}^{-1}\right] \cdot{ }^{a} \mathrm{H}_{2} \mathrm{O}-\mathrm{SEC}$, eluent: water/0.3 M formic acid $/ 0.5 \mathrm{~g} \mathrm{~L}{ }^{-1} \mathrm{NaCl}$; temperature: $30{ }^{\circ} \mathrm{C}$;

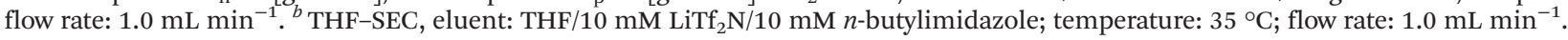




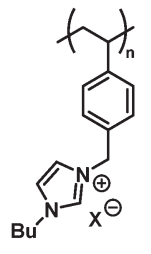

a

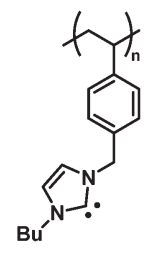

b

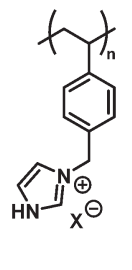

c

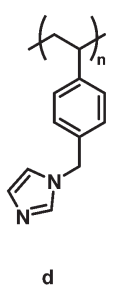

d
For 3: $\mathrm{X}=\mathrm{Cl}$; for $4: \mathrm{X}=\mathrm{Tf}_{2} \mathrm{~N}$

Fig. 3 Representation of possible different side chain transformations occurring during the ESI or MALDI ionization process for 3: (3a) the side chain still represents the IL repeating unit; (3b) hydrogen chloride is released forming a $\mathrm{N}$-heterocyclic carbene $(\mathrm{NHC})$; $(3 \mathrm{c})$ degradation of the $n$-butyl side chain; and ( $3 \mathrm{~d}$ ) degradation of the $n$-butyl side chain by release of hydrogen chloride forming an imidazole.

molecular structure of 3 and 4 . Tenhu and coworkers ${ }^{17}$ used MALDI-ToF MS characterization to identify the molecular weight as well as the dispersity of their prepared PILs.

Although we could not reproduce the MALDI-ToF MS measurements for our systems with the conditions given (refer to the ESI Fig. S3 $\uparrow$ ), we obtained a mass spectrum of polymer 3-1 $\left(M_{\mathrm{n}}=2000 \mathrm{~g} \mathrm{~mol}^{-1}\right)$ by employing the non-acidic matrix material trans-2-[3-(4-tert-butylphenyl)-2-methyl-2-propenylidene] malonitrile (DCTB) (Fig. 4) and methanol as solvent. In contrast to ESI-MS, MALDI-ToF MS has the advantage to form mainly single charged species. The formation of single charged species is crucial for the detection of polymer (3) as during the ionization process different side reactions can occur (Fig. 3).

The high affinity of chloride acting as a H-bond acceptor is responsible for the unexpected ionization process. ${ }^{33}$ According to the mass spectrometric data, the chloride counter ion is prone to be separated from the polymer chain, resulting in a $N$-heterocyclic carbene as illustrated in (3b) with $\mathrm{m} / \mathrm{z}=240.2$ Th. ${ }^{34}$ Furthermore, in accordance with the work by Kroon et al. ${ }^{35}$ ILs bearing chloride as counter ion release alkyl chloride at elevated temperature (approx. $250{ }^{\circ} \mathrm{C}$ in the case of [BMIM]Cl). Thus, 3c and 3d were detected as minor products during mass spectrometric analysis. The signals of the highest intensity (for single charged species) can be assigned to a mixture of species a and $\mathbf{b}$ (refer to Fig. 3). The detection of the polymer is attributed - in most of the cases - to the protonation of only one protonated carbene species $\mathbf{b}$ in the polymer chain while the other repeating units stay in the carbene form. In some cases, however, the ionization of only one repeating unit of the neutral polymer chain is induced by the sodium ion (refer to the structures in Table S4 and S5 $\dagger$ ). In contrast to ESI-MS analysis, the molecular weight distribution obtained by MALDI-ToF MS analysis is limited by the dispersity of the polymer $(\theta<1.2) .{ }^{36}$ Thus, only low molecular weight PIL polymers of rather narrow dispersities are characterized with MALDI-ToF MS. Interestingly, the linear mode of MALDI-ToF MS revealed a better resolution compared to the reflectron mode. This observation may be due to the broad dis-
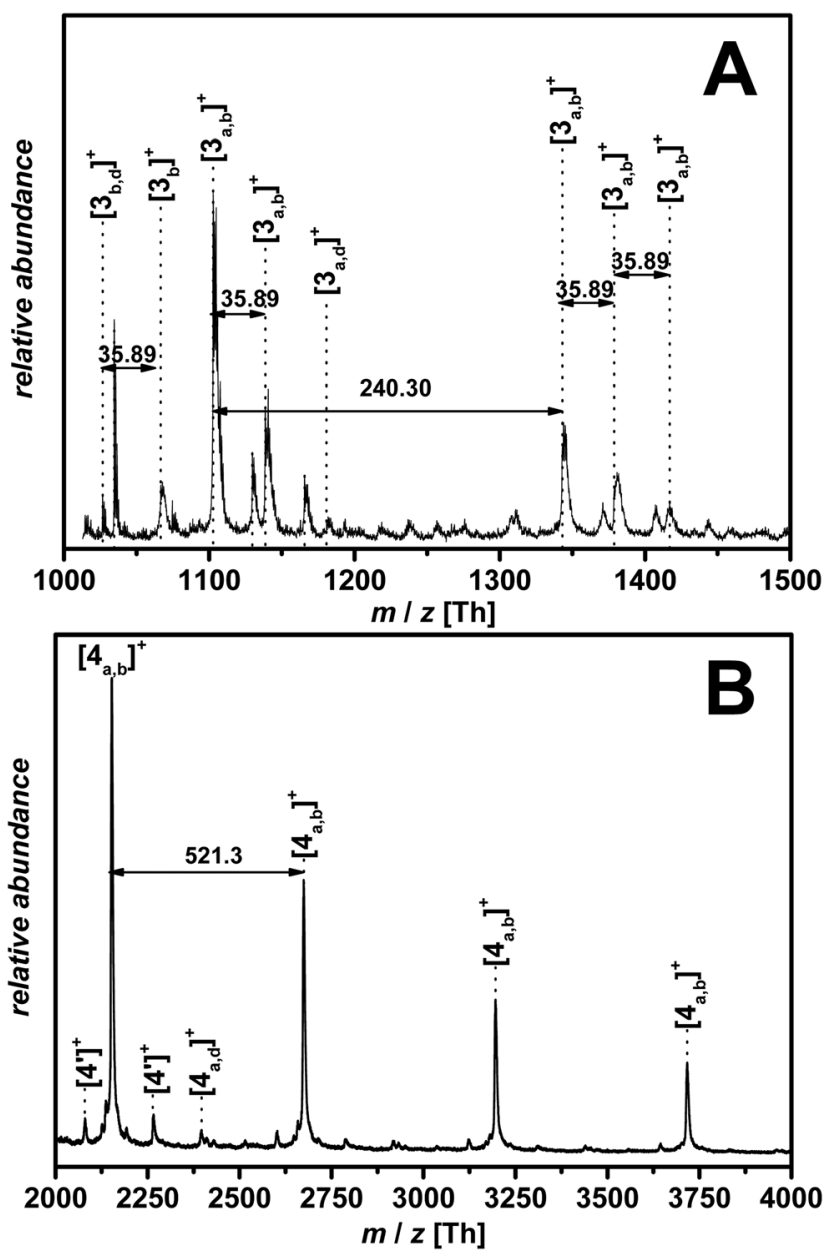

Fig. 4 Zoom of the MALDI-ToF spectrum of (A) p([BVBIM]Cl) (3-1, Table 1) $\left(M_{w}=1900 \mathrm{~g} \mathrm{~mol}^{-1}\right)$ and (B) $p\left([B V B I M] T f_{2} N\right)(4)$ in the representative area of the mass spectrum with the assigned peaks employing DCTB as matrix material, respectively. Please refer to Tables S2 and S3 in the $\mathrm{ESI} \dagger$ for the list of assignments.

persity of the sample whereas the reflectron mode normally enhances the resolution in the case of a narrowly distributed polymer.

Fig. 4(A) and 6(A) illustrate the MALDI-ToF as well as the ESI-MS spectrum obtained for $\mathrm{p}([\mathrm{BVBIM}] \mathrm{Cl})$ (3). Due to the different side products formed during the measurements, the mass spectrometric analysis of PILs bearing chloride counter ions is highly restricted to the chain length. Thus, only very low molecular weights (approx. $M_{\mathrm{w}}=2000 \mathrm{Da}$ ) were observed in spectra with appropriately separated signals.

Due to the preference to form single charged species during MALDI-ToF MS analysis, the separation of hydrogen chloride from the polymer chain can be found in a MALDI-ToF spectrum $(\mathrm{m} / \mathrm{z}=35.8 \mathrm{Th})$. Furthermore, also the endgroup of the polymer (initiator of RAFT agent) or the degradation of the trithiocarbonate to the corresponding thiol can be found in the ESI-MS spectrum (marked with ' for a thiol and ${ }^{*}$ for the initiator as endgroup, Fig. 6(A)). In order to identify the different endgroup combinations of a RAFT polymerization 
mixture, it is necessary to analyze the polymers with MALDIToF MS. The value of the repeating unit $(\mathrm{m} / z=240.3 \mathrm{Th})$ between two $\left[3_{\mathrm{a}, \mathrm{b}}\right]^{+}$peaks is in good agreement with the theoretical value $\left(\mathrm{m} / \mathrm{z}_{\text {(theo.) }}=240.2 \mathrm{Th}\right)$. As already discussed, the chloride degrades the alkyl chain $\left(\left[3_{\mathrm{b}, \mathrm{d}}\right]^{+}\right.$and $\left.\left[3_{\mathrm{a}, \mathrm{d}}\right]^{+}\right)$, however, these signals are of minor intensity (Fig. 4(A)).

Also, a RAFT endgroup conversion was studied dispersing the polymer in THF for three days. After three days, THF was evaporated, the polymer dissolved in methanol and mixed with the matrix in a ratio of 10:1 (matrix: sample). Clearly, THF reacted with the RAFT moiety ${ }^{38}$ as indicated by the MALDI-ToF MS measurements with the identified peaks [3 $\mathrm{OH}]$ and $\left[3 \mathrm{SO}_{2}\right]$ (refer to the ESI Fig. S4† and Fig. 5).

Most evident are two adjacent peaks with a $\mathrm{m} / \mathrm{z}$ difference of 64 Th. According to Benicewicz and coworkers, ${ }^{37}$ trithiocarbonates are prone to be oxidized to the corresponding sulfonic acid in THF after storage for $48 \mathrm{~h}$, and to release gaseous $\mathrm{SO}_{2}$ (64 Th) to form the hydroxyl endgroup (as matrix the team employed dithranol doped with 0.01 M AgTFA). As observed for methanol as solvent, gaseous $\mathrm{HCl}$ is released during the ionization process, resulting in an uncharged polymer.

Fig. 4(B) and 6(B) illustrate the MALDI-ToF as well as the ESI-MS spectrum obtained for $\mathrm{p}\left([\mathrm{BVBIM}] \mathrm{Tf}_{2} \mathrm{~N}\right) 4$. In contrast to the counter ion $\mathrm{Cl}^{-}$of (3) that shows a high $\mathrm{H}$-bond acceptor affinity, the weakly coordinating counter ion $\mathrm{Tf}_{2} \mathrm{~N}^{-}$of 4 does not interact with the protons of the imidazolium ring. The repeating unit between two $[4]^{+}$peaks $(\mathrm{m} / \mathrm{z}=521.1 \mathrm{Th})$ agrees well with the theoretical value $\left(m / z_{\text {(theo. })}=521.1 \mathrm{Th}\right)$.

As observed in the MALDI-ToF measurements as well, the quality of the ESI-MS measurement correlates with the molecular weight of the polymer. The repeating unit of $\mathrm{p}([\mathrm{BVBIM}] \mathrm{Cl})$ (3) is present in four species (please refer to Fig. 3). The permutation of these processes together with the increasing chain length, multiple charges, and whether a proton or a sodium ion ionizes the polymer, results in high amounts of detectable ions. However, the degradation of the alkyl side chain (Fig. 3c and d) is observed with a limited probability. Thus, it is not surprising that - especially for high-molecular weight polymers - the spectrum is complex. The assignment of the dominant peaks is summarized in Table S4 in the ESI. $\dagger$

Furthermore, the Coulomb interactions of $\mathrm{Tf}_{2} \mathrm{~N}^{-}$appear to be stronger compared to $\mathrm{Cl}^{-}$and thus ESI-MS measurements

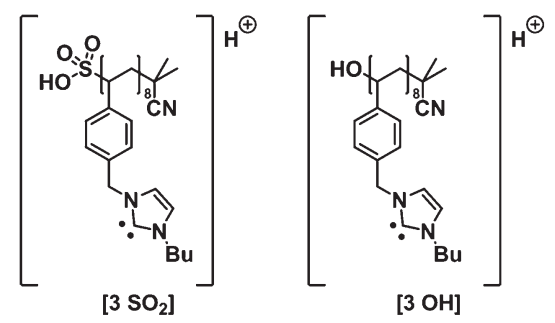

Fig. 5 Chemical structures assigned in the MALDI spectrum of $\mathrm{p}([\mathrm{BVBIM}] \mathrm{Cl})(3)\left(M_{\mathrm{w}}=1900 \mathrm{~g} \mathrm{~mol}^{-1}\right)$. PIL structure with a sulfonic acid endgroup and a hydroxyl endgroup. ${ }^{37}$ The $\mathrm{m} / \mathrm{z}$ difference of both peaks originates from the loss of $\mathrm{SO}_{2}$.
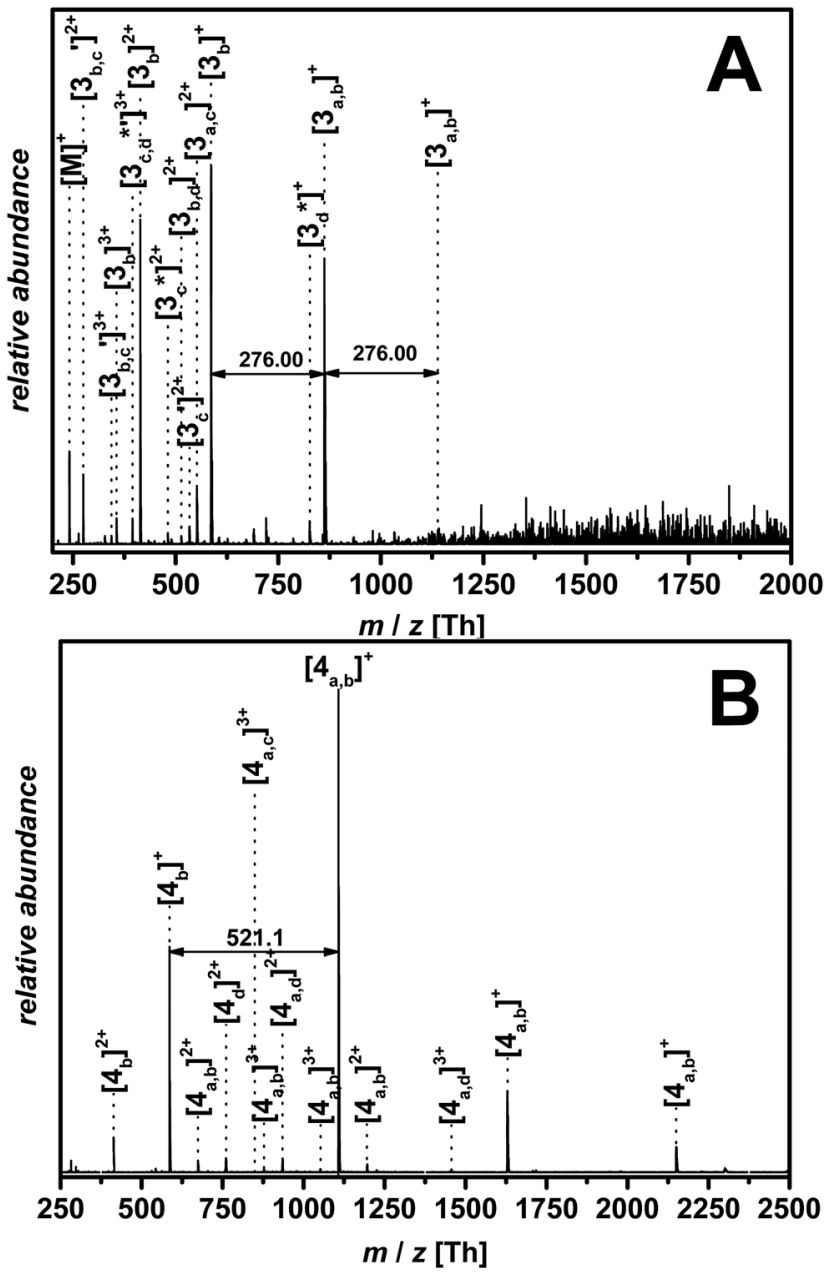

Fig. 6 Zoom of ESI-MS spectra of (A) p([BVBIM]Cl) (3) with a molecular weight of $M_{w}=1900 \mathrm{~g} \mathrm{~mol}^{-1}$ measured in THF/MeOH $(3: 2, \mathrm{v} / \mathrm{v})$ and (B) $\mathrm{p}\left([\mathrm{BVBIM}] \mathrm{Tf}_{2} \mathrm{~N}\right)(4)$ measured in a mixture of acetonitrile/water $(1: 1, \mathrm{v} / \mathrm{v})$. Please refer to the ESI† for a list of the assignments (Tables S4 and S5 $\dagger$ ).

lead to clear spectra (Fig. 6(B)). The signal difference of $\mathrm{m} / \mathrm{z}=$ 521.1 Th is assigned to the molecular weight of the monomer unit $\left(\mathrm{m} / \mathrm{z}_{\text {(theo.) }}=521.1 \mathrm{Th}\right)$. The thiocarbonyl thio endgroup of 4 is clearly identified (see Table S5 $\dagger$ ). The ESI-MS analysis of the PIL bearing $\mathrm{Tf}_{2} \mathrm{~N}^{-}$as counter ion is easier to evaluate since there are far less side events affecting the polymer chain during the ionization process compared to $\mathrm{p}([\mathrm{BVBIM}] \mathrm{Cl})(3)$ polymers.

To demonstrate the versatility of the employed approach, [BVBIM]Cl (1) and another monomer, i.e. 1,2-dimethyl-3-( $p$ vinylbenzyl)-1 $H$-imidazol-3-ium bis(trifluoromethane-sulfonyl)imide ([DMVBIM] $\mathrm{Tf}_{2} \mathrm{~N}(5)$, were applied for spatially resolved light-induced surface modification. Fig. 7 details the graftingfrom approach of the RAFT polymerization of $\mathbf{1}$ and $\mathbf{5}$. The photoenol RAFT agent $7^{\prime}$ was photopatterned via photoenol chemistry onto maleimide-functionalized silicon wafers 6. Subsequently, $\mathbf{1}$ and $\mathbf{5}$ were polymerized on the surfaces 7 by a grafting-from approach leading to highly functionalized patterned structures $(\mathbf{8 a}, \mathbf{8 b})$. 

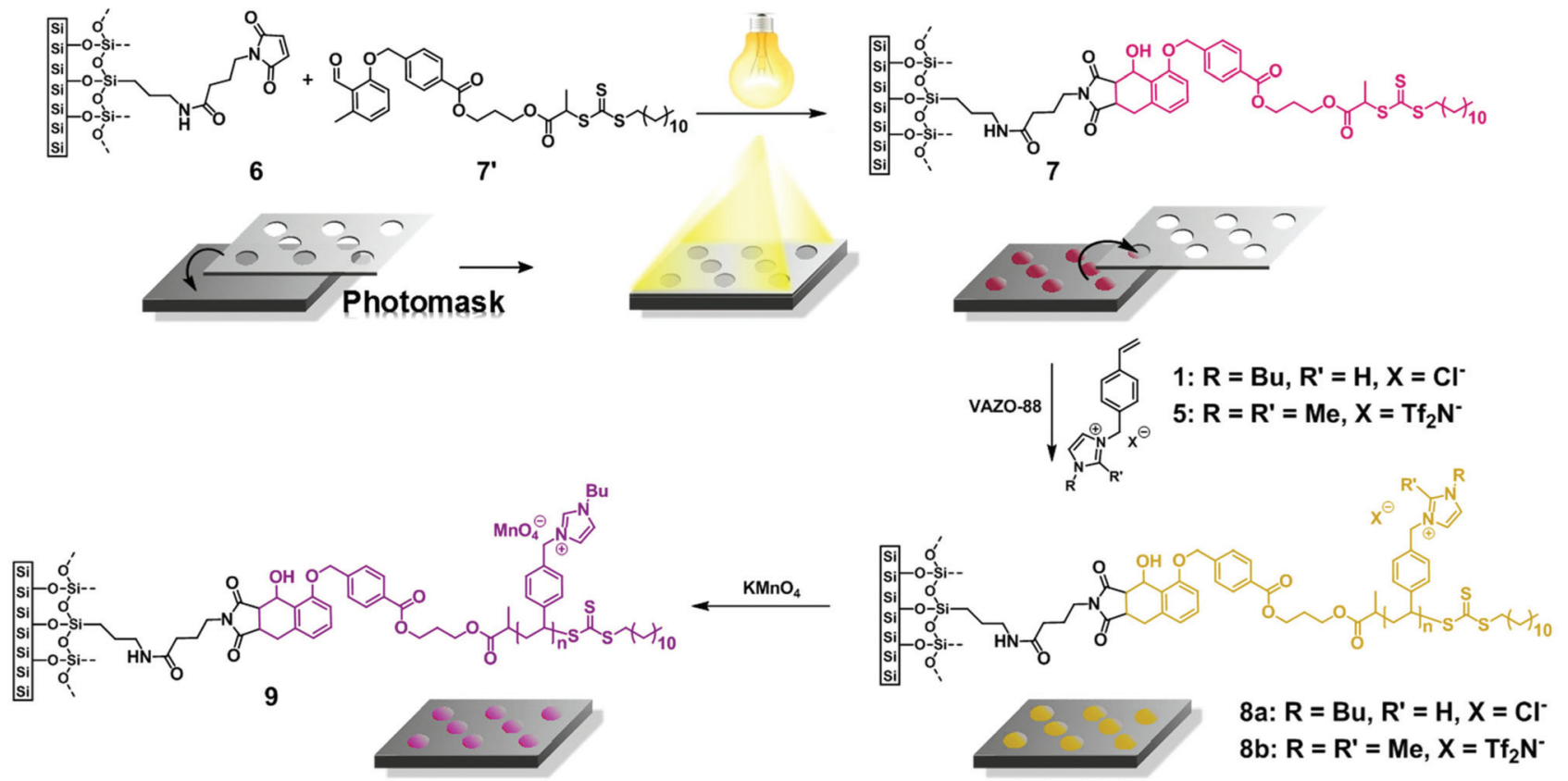

Fig. 7 Schematic illustration of the surface functionalization for the spatially resolved surface functionalization of silicon wafers with (1) and (5). (3-Aminopropyl)triethoxysilane (APTES)-coated silicon wafers were coated with 4-maleimidobutyroyl chloride to achieve maleimide-functionalized surfaces (6). After irradiation, the surfaces covered with a photomask with an ARIMED B6 lamp $\left(\lambda_{\max }=320 \mathrm{~nm}\right.$ ) in a solution of the photoenol functional CTA to result in (7) followed by RAFT polymerization of (1) from the surface. Subsequent salt metathesis of $(8 \mathrm{a})$ with $\mathrm{KMnO}_{4}$ resulted in a highly violet colored meander pattern of $\mathrm{p}\left([\mathrm{BVB} I \mathrm{M}] \mathrm{MnO}_{4}\right)(9)$.

First, APTES-coated surfaces, ${ }^{39}$ thoroughly cleaned by rinsing them with toluene, acetone, methanol and Milli Q water, were placed in a solution of freshly prepared 4-maleimidobutyroyl chloride in dichloromethane to obtain maleimide-coated surface 6 acting as dienophile in the subsequent photoenol reaction with the CTA $\left(7^{\prime}\right)$ in acetonitrile (due to its low absorption in the UV/Vis area) for 2.5 hours.

Therefore, a photomask is placed on the maleimide-coated surfaces 6, and irradiated with an ARIMED B6 lamp $\left(\lambda_{\max }=\right.$ $320 \mathrm{~nm}$ ) for spatially resolved photopatterning of the samples with a RAFT agent for subsequent RAFT polymerization of 1 and 5. The surface was rinsed thoroughly with THF, acetone, methanol and Milli $\mathrm{Q}$ water, dried under a flow of nitrogen, and analyzed via XPS and ToF-SIMS, respectively.

The polymerization of [BVBIM]Cl (1) was subsequently carried out in a DMSO/DMF mixture $(1: 1, \mathrm{v} / \mathrm{v})$ with a monomer concentration of approx. $0.6 \mathrm{~mol} \mathrm{~L}^{-1}$. After addition of 2-(dodecylthiocarbonothioyl-thio)propionic acid (DoPAT) as sacrificial RAFT agent and VAZO-88 as radical starter, the mixture was degassed via three consecutive freeze-pump-thaw cycles. As demonstrated by Zamfir et al., ${ }^{40}$ the grafting-from approach is best carried out in a $1: 1$ ratio of CTA: initiator. The high initiator concentration used is necessitated by the hopping migration mechanism explaining the steady termination of adjacent radicals on the surface. The polymerization was allowed to proceed for $7 \mathrm{~h}$ (50\% conversion), ensuring the formation of high-molecular weight polymer on the surface.
The residual monomer as well as potential polymer attached via physisorption was removed by thorough rinsing of the functionalized surface 8a with Milli Q water, methanol, acetone, and Milli Q water followed by immersing the surface in methanol for $12 \mathrm{~h}$. Subsequently, the surface was ultrasonically treated in a solution containing $0.5 \mathrm{~g} \mathrm{~L}^{-1}$ ammonium chloride and rinsed thoroughly with acetone.

Since $\mathrm{p}\left([\mathrm{DMVBIM}] \mathrm{Tf}_{2} \mathrm{~N}(55 \%\right.$ conversion after $7 \mathrm{~h})$ is highly hydrophobic, the residual monomer as well as potential polymer attached via physisorption was removed by thorough rinsing of the functionalized surface $\mathbf{8 b}$ with acetone, dichloromethane, methanol and Milli Q water followed by treating the surface in a solution containing $1.0 \mathrm{~g} \mathrm{~L}^{-1} \operatorname{LiTf}_{2} \mathrm{~N}$. Residual salt was removed via ultrasonification in acetone.

Fig. 8 depicts the corresponding XP spectra. The $\mathrm{C} 1 \mathrm{~s}$ spectrum shows the $(\mathrm{C}-\mathrm{C}, \mathrm{C}-\mathrm{H})$ component at $285.0 \mathrm{eV},(\mathrm{C}-\mathrm{O}, \mathrm{C}-\mathrm{N})$ at $286.4 \mathrm{eV}$ and $(\mathrm{COO}, \mathrm{NCO})$ at $288.5 \mathrm{eV}$, which are present in the maleimide (surface 6) and the photoenol (surface 7). ${ }^{41}$ The photo-ligation of 7 was evidenced by the sulfur signal at 163.6 $\mathrm{eV}$ indicating the presence of the trithiocarbonate group (refer to Fig. S13 in the ESI $\dagger$ ). ${ }^{42}$

After the surface-initiated polymerization to obtain $\mathbf{8 a}$, the formation of the signal at $401.8 \mathrm{eV}$, which is characteristic for the imidazole group $\left(\mathrm{N}^{+}\right)$, is detected in the $\mathrm{N}$ 1s spectrum. The (protonated) amine signal at $401.8 \mathrm{eV}$ in the XPS increases from 0.3 at\% (surface 7) obviously stemming from a contamination (e.g. unreacted APTES) to 8.9 at\% (surface 8a), which 

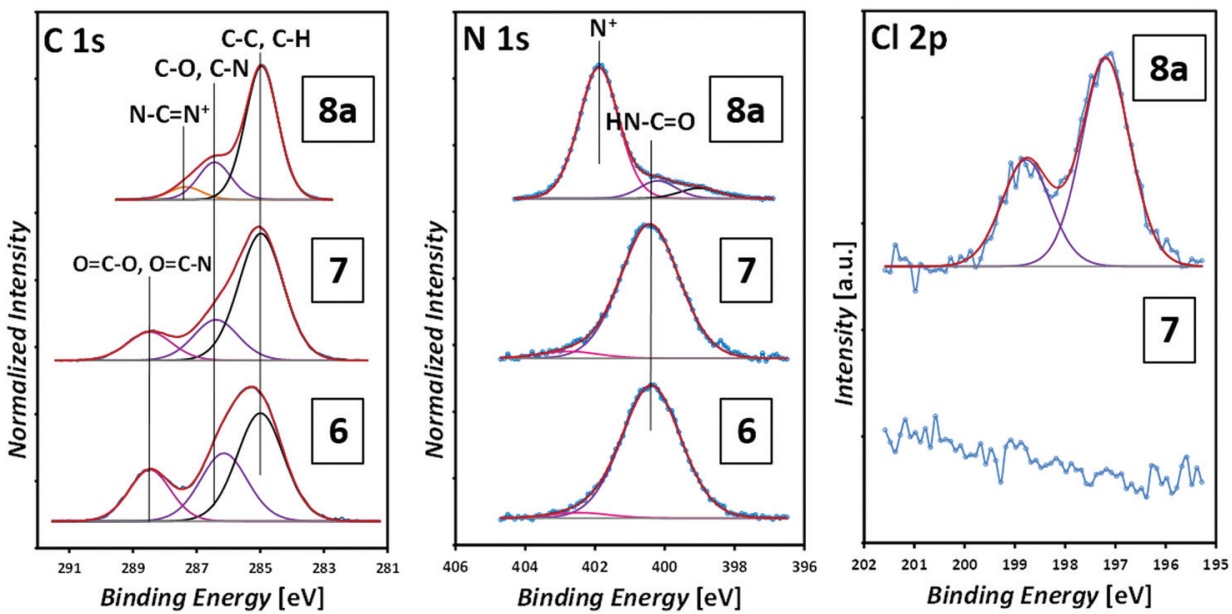

Fig. 8 XP spectra of the maleimide functionalization (6), photoenol functionalization (7) and the grafting-from polymerization (8a) with [BVBIM]Cl (1).

can be assigned to the formation of the imidazole group. Most characteristically, the presence of a signal originating from $\mathrm{Cl} 2 \mathrm{p}$ indicates the counter ion, which is absent on the APTES/ maleimide-coated surface $\mathbf{6}$ as well as on the RAFT agent-functionalized surface 7. ToF-SIMS images of the $\mathrm{C}_{12} \mathrm{H}_{25} \mathrm{~S}^{-}, \mathrm{S}^{-}$, $\mathrm{C}_{16} \mathrm{H}_{21} \mathrm{~N}_{2}{ }^{+}$(surface 8a) and $\mathrm{C}_{14} \mathrm{H}_{17} \mathrm{~N}_{2}{ }^{+}$(surface 8b) fragments are shown in Fig. 9. ToF-SIMS images clearly confirm the covalent attachment of $7^{\prime}$ precisely following the dotted shape of the photomask. As expected, in the areas covered by the photomask, no photoenol reaction proceeded and thus no characteristic signals stemming from 7 were observed. After successful grafting-from of [BVBIM]Cl (1), ToF-SIMS measurements in the positive mode confirm the presence of the repeating unit $\left(\mathrm{C}_{16} \mathrm{H}_{21} \mathrm{~N}_{2}{ }^{+} ; \mathrm{m} / \mathrm{z}=241.20 \mathrm{Th}\right)$ on the surface 8a. Furthermore, successful grafting of [DMVBIM] $\mathrm{Tf}_{2} \mathrm{~N}$ (5) was also confirmed by its characteristic repeating unit $\left(\mathrm{C}_{14} \mathrm{H}_{17} \mathrm{~N}_{2}{ }^{+}\right.$; $m / z=213.13 \mathrm{Th}$ ) on the surface 8a. Since this surface was prepared as proof-of-principle for the ToF-SIMS measurement, no XPS measurements were carried out on surface $\mathbf{8 b}$. In addition, in order to confirm the presence of the ionic nature of the PIL attached to the surface, the substrate was immersed in $\mathrm{KMnO}_{4}$ (refer to Fig. 7). After dipping the substrate into a $50 \mathrm{mM}$ $\mathrm{KMnO}_{4}$ solution for only two to three seconds, the surface was thoroughly rinsed with methanol and Milli Q water. Clearly, the meander structure - assigned to the successful photopatterning - became visible immediately. The stability of PILs with a redox-active counter ion was shown by Mecerreyes and coworkers. ${ }^{43}$

Thus, it is believed that the ion exchange of $\mathrm{Cl}^{-}$against $\mathrm{MnO}_{4}{ }^{-}$proceeded on the surface $9 .{ }^{44}$ It has to be noted that the brownish color of the pattern can be assigned to $\mathrm{MnO}_{2}$ that was formed due to the rapid degradation of $\mathrm{MnO}_{4}{ }^{-}$ (Fig. 9). The meander structure was used for this experiment to show the versatility of the presented photochemically induced approach.

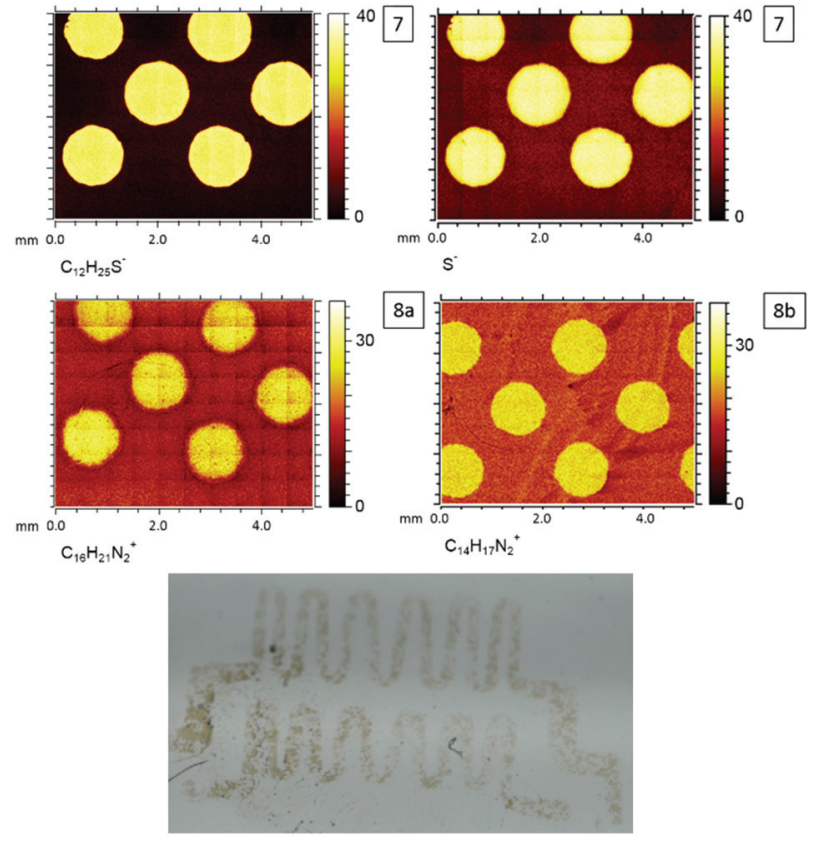

Fig. 9 ToF-SIMS images of photoenol functionalization (7), graftingfrom polymerization (8a) with $[B V B I M] C l(1)$, grafting-from polymerization (8b) with [DMVBIM]Tf ${ }_{2} \mathrm{~N}$ (5) and detail of a photograph of the violet colored meander pattern of $\mathrm{p}\left([\mathrm{BVBIM}] \mathrm{MnO}_{4}\right)(9)$ resulting from the salt metathesis of $8 \mathrm{a}$ with $\mathrm{KMnO}_{4}$. Please refer to Fig. $\mathrm{S} 16 \uparrow$ for the complete photograph.

\section{Experimental}

Synthesis of 1-butyl-3-(4'-vinylbenzyl)-1H-imidazol-3-ium chloride ([BVBIM]Cl, 1)

The IL was prepared by a slightly modified procedure by Bara et $a .^{27} 9.00 \mathrm{~g} n$-butylimidazole (72.5 mmol, 1.00 eq.) was dissolved in $100 \mathrm{~mL}$ chloroform and cooled to $0{ }^{\circ} \mathrm{C}$. Sub- 
sequently, $15.4 \mathrm{~mL}$ vinylbenzyl chloride (16.6 g, $108.7 \mathrm{mmol}$, 1.50 eq.) was added. The mixture was stirred at $50{ }^{\circ} \mathrm{C}$ for $24 \mathrm{~h}$. The mixture was extracted with water $(3 \times 25 \mathrm{~mL})$, evaporated at reduced pressure to get rid of the residue organic solvents, and freeze-dried. $17.5 \mathrm{~g}$ of product 1 (63.1 mmol, 87\%) was received as a colorless, highly viscous liquid.

${ }^{1} \mathrm{H}$ NMR (400 MHz, DMSO- $\left.d_{6}, 298 \mathrm{~K}\right): \delta=9.72(\mathrm{~s}, 1 \mathrm{H}$, $\mathrm{N}=\mathrm{CH}-\mathrm{N}), 7.91\left(\mathrm{~d},{ }^{3} \mathrm{~J}=13.8 \mathrm{~Hz}, 2 \mathrm{H}, \underline{\mathrm{Im}}-\mathbf{H}\right), 7.50\left(\mathrm{~d},{ }^{3} \mathrm{~J}=\right.$ $8.2 \mathrm{~Hz}, 2 \mathrm{H}, \underline{\mathrm{Ph}}-\mathbf{H}$ ), 7.46 (d, ${ }^{3} J=8.2 \mathrm{~Hz}, 2 \mathrm{H}, \underline{\mathrm{Ph}}-\mathbf{H}$ ), 6.72 (dd, $\left.{ }^{3} J(\mathrm{Z})=11.0 \mathrm{~Hz},{ }^{3} J(\mathrm{E})=17.7 \mathrm{~Hz}, 1 \mathrm{H}, \mathrm{H}_{2} \mathrm{C}=\mathrm{CH}\right), 5.85\left(\mathrm{~d},{ }^{3} J(\mathrm{E})=\right.$

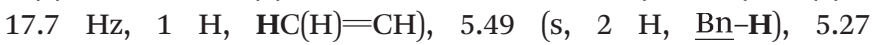
$\left(\mathrm{d},{ }^{3} \mathrm{~J}(\mathrm{Z})=11.0 \mathrm{~Hz}, 1 \mathrm{H}, \mathrm{HC}(\mathrm{H})=\mathrm{CH}\right), 4.20(\mathrm{t}, \overline{3}=7.2 \mathrm{~Hz}$, $2 \mathrm{H}, \mathrm{N}-\mathrm{CH}_{2}-\mathrm{CH}_{2}$ ), 1.92-1.60 (m, $\left.2 \mathrm{H}, \mathrm{CH}_{2}-\mathrm{CH}_{2}-\mathrm{CH}_{2}\right), 1.43-1.02$ $\left(\mathrm{m}, 2 \mathrm{H}, \mathrm{CH}_{2}-\mathrm{CH}_{2}-\mathrm{CH}_{3}\right), 0.87\left(\mathrm{t},{ }^{3} J(\mathrm{Z})=7.5 \mathrm{~Hz}, 3 \mathrm{H}, \mathrm{CH}_{2}-\right.$ $\left.\mathrm{CH}_{3}\right) \mathrm{ppm}$.

${ }^{13} \mathrm{C}-\mathrm{NMR}\left(100 \mathrm{MHz}, \mathrm{DMSO}-d_{6}, 298 \mathrm{~K}\right): \delta=137.56$ (C), 136.17 (C), $135.93(\mathrm{CH}), 134.30(\mathrm{CH}), 128.67(2 \mathrm{CH}), 126.67(2 \mathrm{CH})$, $\left.122.79(\mathrm{CH}), 122.54(\mathrm{CH}), 115.29 \mathrm{CH}_{2}\right), 51.65\left(\mathrm{CH}_{2}\right), 48.67$ $\left(\mathrm{CH}_{2}\right), 31.24\left(\mathrm{CH}_{2}\right), 18.79\left(\mathrm{CH}_{2}\right), 13.26\left(\mathrm{CH}_{3}\right) \mathrm{ppm}$.

Analytical data is in accordance to the results obtained by He et al. ${ }^{20}$

Synthesis of 1-butyl-3-(4'-vinylbenzyl)-1H-imidazol-3-ium bis(trifluoromethanesulfonyl)imide ([BVBIM] $\left.\mathbf{T f}_{2} \mathbf{N}, 2\right) .4 .50 \mathrm{~g}$ $n$-butylimidazole $(36.2 \mathrm{mmol}, 1.00$ eq.) was dissolved in $100 \mathrm{~mL}$ chloroform and cooled to $0^{\circ} \mathrm{C}$. Subsequently, $8.3 \mathrm{~g}$ vinylbenzyl chloride $(54.4 \mathrm{mmol}, 1.50$ eq.) was added. The mixture was stirred at $50^{\circ} \mathrm{C}$ for $24 \mathrm{~h}$. The mixture was extracted with water $(2 \times 100 \mathrm{~mL})$, and evaporated at reduced pressure to get rid of the residual organic solvents. Afterwards, $10.4 \mathrm{~g}$ $\operatorname{LiTf}_{2} \mathrm{~N}$ (36.2 mmol, 1.00 eq.) was added. The reaction was allowed to proceed overnight at ambient temperature. The mixture was extracted with ethyl acetate $(3 \times 75 \mathrm{~mL})$. The combined organic solvents were washed with water $(1 \times 100 \mathrm{~mL})$, and dried over sodium sulfate. $15.97 \mathrm{~g}$ of product 2 (30.7 mmol, 84\%) was received as a colorless liquid.

${ }^{1} \mathrm{H}$ NMR (400 MHz, DMSO- $\left.d_{6}, 298 \mathrm{~K}\right): \delta=9.29(\mathrm{~s}, 1 \mathrm{H}$, $\mathrm{N}=\mathrm{CH}-\mathrm{N}), 7.77(\mathrm{~s}, 2 \mathrm{H}, \underline{\mathrm{Im}}-\mathbf{H}), 7.52\left(\mathrm{~d},{ }^{3} \mathrm{~J}=8.1 \mathrm{~Hz}, 2 \mathrm{H}, \underline{\mathrm{Ph}}-\mathbf{H}\right)$, $7.43\left(\mathrm{~d},{ }^{3} \mathrm{~J}=8.2 \mathrm{~Hz}, 2 \mathrm{H}, \underline{\mathrm{Ph}}-\mathbf{H}\right), 6.74\left(\mathrm{dd},{ }^{3} J(\mathrm{Z})=11.0 \mathrm{~Hz},{ }^{3} J(\mathrm{E})\right.$ $\left.=17.7 \mathrm{~Hz}, 1 \mathrm{H}, \mathrm{H}_{2} \mathrm{C}=\mathrm{CH}\right), 5.86\left(\mathrm{~d},{ }^{3} J(\mathrm{E})=17.7 \mathrm{~Hz}, 1 \mathrm{H}, \mathbf{H C}\right.$ $(\mathrm{H})=\mathrm{CH}), 5.42(\mathrm{~s}, 2 \mathrm{H}, \underline{\mathrm{Bn}}-\mathbf{H}), 5.29\left(\mathrm{~d},{ }^{3} J(\mathrm{Z})=11.0 \mathrm{~Hz}, 1 \mathrm{H}, \mathbf{H C}\right.$ $(\mathrm{H})=\mathrm{CH}$ ), $4.19\left(\mathrm{t},{ }^{3} \mathrm{~J}=7.2 \mathrm{~Hz}, 2 \mathrm{H}, \mathrm{N}-\mathrm{CH}_{2}-\mathrm{CH}_{2}\right.$ ), 1.79 (quin, $\left.{ }^{3} J=7.5 \mathrm{~Hz}, 2 \mathrm{H}, \mathrm{CH}_{2}-\mathrm{CH}_{2}-\mathrm{CH}_{2}\right), 1.28\left(\mathrm{~m}, 2 \mathrm{H}, \mathrm{CH}_{2}-\mathrm{CH}_{2}-\mathrm{CH}_{3}\right)$, $0.90\left(\mathrm{t},{ }^{3} J=7.5 \mathrm{~Hz}, 3 \mathrm{H}, \mathrm{CH}_{2}-\mathrm{CH}_{3}\right) \mathrm{ppm}$.

${ }^{13} \mathrm{C}\left\{{ }^{1} \mathrm{H}\right\}$ NMR (100 MHz, DMSO- $\left.d_{6}, 298 \mathrm{~K}\right): \delta=139.32(\mathrm{C})$, 135.90 (C), $135.83(\mathrm{CH}), 131.52(\mathrm{CH}), 129.36$ (2 CH), 127.49 (2 $\mathrm{CH}), 122.30(\mathrm{CH}), 122.08(\mathrm{CH}), 119.95\left(\mathrm{q},{ }^{1} J=318.0 \mathrm{~Hz}\right.$, $\left.\mathrm{CF}_{3}\right), 115.88\left(\mathrm{CH}_{2}\right), 53.59\left(\mathrm{CH}_{2}\right), 50.31\left(\mathrm{CH}_{2}\right), 32.07\left(\mathrm{CH}_{2}\right)$, $19.49\left(\mathrm{CH}_{2}\right), 13.39\left(\mathrm{CH}_{3}\right) \mathrm{ppm}$.

Analytical data is in accordance to the results obtained by He et al. ${ }^{20}$

Synthesis of 1,2-dimethyl-3-(4'-vinylbenzyl)-1H-imidazol-3ium bis(trifluoromethanesulfonyl)imide ([DMVBIM] $\mathrm{Tf}_{2} \mathrm{~N}$, 5). A Schlenk tube was charged with $2.00 \mathrm{~g}$ 1,2-dimethylimidazole (20.8 mmol, 1.00 eq.), dissolved in $10 \mathrm{~mL} \mathrm{CHCl}_{3}$ and cooled to $0{ }^{\circ} \mathrm{C}$. Subsequently, $3.81 \mathrm{~g}$ vinylbenzyl chloride (25.0 mmol, 1.20 eq.) was added and the tube was heated from $0{ }^{\circ} \mathrm{C}$ to $50{ }^{\circ} \mathrm{C}$. The mixture was stirred at $50{ }^{\circ} \mathrm{C}$ for $24 \mathrm{~h}$. The mixture was extracted with water (slow phase separation). Afterwards, $7.17 \mathrm{~g} \operatorname{LiTf}_{2} \mathrm{~N}(25.0 \mathrm{mmol}, 1.2 \mathrm{eq}$.) was added and the mixture stirred for $3 \mathrm{~d}$ at ambient temperature. The mixture was extracted with ethyl acetate $(3 \times 40 \mathrm{~mL})$ und the organic solvent washed with water $(1 \times 50 \mathrm{~mL})$. The organic layers were dried over sodium sulfate and the solvent was evaporated at reduced pressure. $8.67 \mathrm{~g}$ of product 5 (17.6 mmol, 85\%) was received as a slightly orange colored liquid.

${ }^{1} \mathrm{H}$ NMR (400 MHz, DMSO- $\left.d_{6}, 298 \mathrm{~K}\right): \delta=7.67\left(\mathrm{~d},{ }^{3} \mathrm{~J}=\right.$ $20.2 \mathrm{~Hz}, 2 \mathrm{H}, \mathrm{Im}-\mathbf{H}), 7.51$ (d, $\left.{ }^{3} J=8.2 \mathrm{~Hz}, 2 \mathrm{H}, \mathrm{Ph}-\mathbf{H}\right), 7.32$ (d, $\left.{ }^{3} J=8.2 \mathrm{~Hz}, 2 \mathrm{H}, \mathrm{Ph}-\mathbf{H}\right), 6.74\left(\mathrm{dd},{ }^{3} J(\mathrm{Z})=11.0 \mathrm{~Hz},{ }^{3} J(\mathrm{E})=17.7\right.$ $\left.\mathrm{Hz}, 1 \mathrm{H}, \mathrm{H}_{2} \mathrm{C}=\mathrm{CH}\right), 5.86\left(\mathrm{~d},{ }^{3} J(\mathrm{E})=17.7 \mathrm{~Hz}, 1 \mathrm{H}, \mathrm{HC}(\mathrm{H})=\mathrm{CH}\right)$, 5.41 (s, $2 \mathrm{H}, \mathrm{Bn}-\mathbf{H}), 5.29$ (d, $\left.{ }^{3} J(\mathrm{Z})=11.0 \mathrm{~Hz}, 1 \mathrm{H}, \mathrm{HC}(\mathrm{H})=\mathrm{CH}\right)$, 3.77 (s, $\left.3 \mathrm{H}, \mathrm{N}-\mathrm{CH}_{3}\right), 2.60$ (s, $\left.3 \mathrm{H}, \mathrm{N}-\mathrm{C}\left(\mathrm{CH}_{3}\right)-\mathrm{N}\right) \mathrm{ppm}$.

${ }^{13} \mathrm{C}\left\{{ }^{1} \mathrm{H}\right\}$ NMR $\left(100 \mathrm{MHz}, \mathrm{DMSO}-d_{6}, 298 \mathrm{~K}\right): \delta=144.66(\mathrm{C})$, 137.42 (C), $135.94(\mathrm{C}), 134.04(\mathrm{CH}), 128.12$ (2 CH), 124.36 (2 CH), $122.69(\mathrm{CH}), 121.24(\mathrm{CH}), 119.57\left(\mathrm{q},{ }^{1} J=321.8 \mathrm{~Hz}\right.$, $\left.\mathrm{CF}_{3}\right), 115.07\left(\mathrm{CH}_{2}\right), 50.46\left(\mathrm{CH}_{2}\right), 34.78\left(\mathrm{CH}_{3}\right), 9.40\left(\mathrm{CH}_{3}\right) \mathrm{ppm}$.

ESI-MS for $\mathrm{C}_{14} \mathrm{H}_{17} \mathrm{~N}_{2}^{+}: m / z=213.14$.

Synthesis of poly[1-butyl-3-(4'-vinylbenzyl)-1H-imidazol3-ium chloride] (3). A Schlenk flask was charged with $2.03 \mathrm{~g}$ 1-butyl-3-(4'-vinylbenzyl)-1 $H$-imidazol-3-ium chloride (1) (7.41 mmol, 200.00 eq.), $1.8 \mathrm{mg}$ 1,1'-azobis(cyclohexanecarbonitrile) (0.00741 mmol, 0.20 eq.) and $12.8 \mathrm{mg}$ 2-cyano-2-propyl dodecyl trithiocarbonate $(0.037 \mathrm{mmol}, 1.00 \mathrm{eq}$.$) . The mixture$ was dissolved in DMSO, degassed by three consecutive freezepump-thaw cycles, filled with nitrogen, and subsequently immersed in a preheated oil bath at $85^{\circ} \mathrm{C}$. The polymerization was stopped by sudden freezing in liquid nitrogen, diluting in water and purging with air. Next, the polymer was purified by dialysis in pure water ( $3 \mathrm{~d}$, a.t., $1 \mathrm{kDa}$ MWCO).

Synthesis of poly[1-butyl-3-(4'-vinylbenzyl)-1H-imidazol-3ium bis(trifluoromethanesulfonyl)imide] (4). A Schlenk flask was charged with $8.00 \mathrm{~g}$ 1-butyl-3-(4'-vinylbenzyl)-1H-imidazol3-ium bis(trifluoromethane) sulfonimide (2) (15.34 mmol, 200.00 eq.), $3.8 \mathrm{mg} \quad 1,1^{\prime}$-azobis(cyclohexanecarbonitrile) (0.0153 mmol, 0.20 eq.) and $26.5 \mathrm{mg}$ 2-cyano-2-propyl dodecyl trithiocarbonate $(0.0767 \mathrm{mmol}, 1.00 \mathrm{eq}$.). The mixture was dissolved in BuCN, degassed by three consecutive freeze-pumpthaw cycles, filled with nitrogen and subsequently immersed in a preheated oil bath at $85{ }^{\circ} \mathrm{C}$. The polymerization was stopped by sudden freezing in liquid nitrogen, diluted in acetone and purging with air. After dialysis (pure water or DMSO for 3 d, a.t., 1 kDa MWCO), the product 4 was obtained as yellow substance depending on the residual monomer as a highly viscous liquid or as a solid.

Synthesis of poly[1-butyl-3-(4'-vinylbenzyl)-1H-imidazol-3ium bis(triluoromethanesulfonyl)imide] (4) by salt metathesis. $21.0 \mathrm{mg}$ poly(1-butyl-3-(4'-vinylbenzyl)- $1 H$-imidazol-3-ium chloride) (8900 $\mathrm{g} \mathrm{mol}^{-1}, 0.0755 \mathrm{mmol}, 1.00 \mathrm{eq}$.) was dissolved in $1 \mathrm{~mL}$ water. Subsequently, $26.0 \mathrm{mg} \operatorname{LiTf}_{2} \mathrm{~N}$ (0.0906 mmol, 1.20 eq.) was added, and the reaction was allowed to proceed for $24 \mathrm{~h}$ at ambient temperature. Next, the product was extracted with ethyl acetate $(2 \times 5 \mathrm{~mL})$, dried over 
sodium acetate, and evaporated at reduced pressure. Product 4 was received as a yellowish solid.

Synthesis of the photoenol-functionalized RAFTagent $\left(7^{\prime}\right)$. The synthesis was followed the protocol of Kaupp et al. ${ }^{42}$

Synthesis of 4-maleimidobutyroyl chloride. The synthesis was followed the protocol of Herrmann et al. ${ }^{45}$

APTES-functionalization of $\mathbf{S i}$ wafer. The $\mathrm{Si}$ surfaces (approx. $1 \times 1 \mathrm{~cm}^{2}$ ) were treated with piranha solution $\left(\mathrm{H}_{2} \mathrm{SO}_{4}: \mathrm{H}_{2} \mathrm{O}_{2}, 4: 1 \mathrm{v} / \mathrm{v}\right)$ for $3 \mathrm{~h}$. Subsequently, the Si wafers were rinsed thoroughly with Milli $\mathrm{Q}$ water and dried under a stream of nitrogen. In a further step, the activated surfaces were placed in a solution of $5.0 \mathrm{~mL}$ APTES, $70.0 \mathrm{~mL}$ toluene and 0.1 vol\% triethylamine and allowed to react overnight at $80{ }^{\circ} \mathrm{C}$. The substrates were rinsed with toluene, acetone and methanol, before being dried under a stream of nitrogen.

Maleimide-functionalization of (APTES) Si wafer. The APTES-functionalized Si substrate was immersed in $55 \mathrm{mM}$ DCM solution of TEA. Equal volume of a $50 \mathrm{mM}$ solution of 4-maleimidobutyroyl chloride in dry dichloromethane was added subsequently under inert atmosphere. The reaction was allowed to proceed for $4 \mathrm{~h}$. The surfaces were rinsed with dichloromethane, methanol and Milli $\mathrm{Q}$ water and left in a petri dish with methanol overnight. Next, the surfaces were rinsed with THF, methanol and Milli Q water.

Photo-patterning of DoPAT-PE $\left(7^{\prime}\right)$ on the maleimide-functionalized Si wafer (6). The substrate was immersed in a $11 \mathrm{mM}$ solution of DoPAT-PE ( $\left.7^{\prime}\right)$ in acetonitrile, and subsequently degassed by purging with nitrogen for 20 minutes. Next, the wafer was irradiated for $2.5 \mathrm{~h}$ (UV lamp: ARIMED B6, $\left.\lambda_{\text {max }}=320 \mathrm{~nm}\right)$. Subsequently, the wafer was rinsed thoroughly with THF, acetone, methanol and Milli Q water and dried under a stream of nitrogen.

Grafting-from polymerization of butylvinylbenzylimidazolium chloride (1). The DoPAT-PE-functionalized substrate 7 was placed in a vial and flushed with argon for 5 minutes. A solution - degassed via three consecutive freeze-pump-thaw cycles - of $5.55 \mathrm{~g}$ butylvinylbenzylimidazolium chloride (1) (20.1 mmol, 1500 eq.), $4.7 \mathrm{mg}$ DoPAT (0.0134 mmol, 1.00 eq.) and $3.3 \mathrm{mg}$ VAZO-88 (0.0134 mmol, 1.00 eq.) was added to the wafer and the vial placed in a preheated custom-built heating block at $85{ }^{\circ} \mathrm{C}$. After $7 \mathrm{~h}$, the polymerization was stopped by sudden cooling in liquid nitrogen and bubbled with air. The solution was dialyzed in deionized water for $3 \mathrm{~d}$ and freeze-dried afterwards. The wafer was rinsed thoroughly with Milli Q water, methanol, acetone and Milli Q water again and left in a petri dish with methanol overnight. The wafer was again rinsed with Milli Q water, methanol and Milli $\mathrm{Q}$ water and left for another $24 \mathrm{~h}$ in a petri dish with methanol. Subsequently, the wafer was rinsed with Milli Q water, methanol and Milli Q water and dried under a stream of nitrogen.

Reaction of PIL-grafted surface (8) with $\mathrm{KMnO}_{4}$. The PILgrafted surface was dipped into a $50 \mathrm{mM}$ solution of $\mathrm{KMnO}_{4}$ in water for 2 to 3 seconds. Subsequently, the surface was rinsed thoroughly with Milli $\mathrm{Q}$ water and dried under a stream of nitrogen.

\section{Conclusions}

In summary, we provide a useful and general synthetic tool to access imidazolium poly(ionic liquids) with styrenic IL monomer units i.e. $\mathrm{p}([\mathrm{BVBIM}] \mathrm{Cl})$ and $\mathrm{p}\left([\mathrm{BVBIM}] \mathrm{Tf}_{2} \mathrm{~N}\right)$ via the RAFT polymerization technique. The mass spectrometric indepth characterization of poly(ionic liquid)s is described giving a detailed account of the molecular structure of these polyelectrolytes. In addition, we present a light-induced photoenol driven avenue to provide spatially resolved functional interfaces. The results of our contribution will facilitate access to the discussed class of poly(ionic liquid)s to further understand their molecular weight dependent physical properties and functions. The surface patterning method can be applied to develop task-specific interfaces.

\section{Acknowledgements}

C. B.-K. acknowledges continued funding from the Karlsruhe Institute of Technology (KIT), the Helmholtz association via the BioInterfaces and the Science and Technology of Nanosystems programs, and the German Research Council (DFG). J. Y. thanks the Max Planck Society for the financial support. Dr Maria Schneider, Katrin Kockler and Andrea Hufendiek (all KIT) are thanked for fruitful discussions regarding SEC measurements.

\section{Notes and references}

1 N. V. Plechkova and K. R. Seddon, Chem. Soc. Rev., 2008, 37, 123-150.

2 M. D. Green and T. E. Long, Polym. Rev., 2009, 49, 291-314.

3 O. Green, S. Grubjesic, S. Lee and M. A. Firestone, Polym. Rev., 2009, 49, 339-360.

4 J. Lu, F. Yan and J. Texter, Prog. Polym. Sci., 2009, 34, 431448.

5 D. Mecerreyes, Prog. Polym. Sci., 2011, 36, 1629-1648.

6 J. Yuan, D. Mecerreyes and M. Antonietti, Prog. Polym. Sci., 2013, 38, 1009-1036.

7 Y. Gu and T. P. Lodge, Macromolecules, 2011, 44, 17321736.

8 H. He, S. Averick, E. Roth, D. Luebke, H. Nulwala and K. Matyjaszewski, Polymer, 2014, 55, 3330-3338.

9 H. Mori, M. Yahagi and T. Endo, Macromolecules, 2009, 42, 8082-8092.

10 J. Texter, V. A. Vasantha, R. Crombez, R. Maniglia, L. Slater and T. Mourey, Macromol. Rapid Commun., 2012, 33, 69-74.

11 K. Vijayakrishna, S. K. Jewrajka, A. Ruiz, R. Marcilla, J. A. Pomposo, D. Mecerreyes, D. Taton and Y. Gnanou, Macromolecules, 2008, 41, 6299-6308.

12 J. Yuan, H. Schlaad, C. Giordano and M. Antonietti, Eur. Polym. J., 2011, 47, 772-781.

13 A. Wilke, J. Yuan, M. Antonietti and J. Weber, ACS Macro Lett., 2012, 1, 1028-1031. 
14 J. E. Bara, C. J. Gabriel, E. S. Hatakeyama, T. K. Carlisle, S. Lessmann, R. D. Noble and D. L. Gin, J. Membrane Sci., 2008, 321, 3-7.

15 Z. Shi, B. S. Newell, T. S. Bailey and D. L. Gin, Polymer, 2014, 55, 6664-6671.

16 F. Jiang, C. Li, H. Fu, Y. Wang, X. Guo and G. Wu, Sci. China Chem., 2015, 58, 716-721.

17 E. Karjalainen, D. F. Izquierdo, V. Marti-Centelles, S. V. Luis, H. Tenhu and E. Garcia-Verdugo, Polym. Chem., 2014, 5, 1437-1446.

18 D. Cordella, A. Kermagoret, A. Debuigne, C. Jérôme, D. Mecerreyes, M. Isik, D. Taton and C. Detrembleur, Macromolecules, 2015, 48, 5230-5243.

19 P. Coupillaud, J. Pinaud, N. Guidolin, J. Vignolle, M. Fèvre, E. Veaudecrenne, D. Mecerreyes and D. Taton, J. Polym. Sci., Part A: Polym. Chem., 2013, 51, 4530-4540.

20 H. He, M. Zhong, B. Adzima, D. Luebke, H. Nulwala and K. Matyjaszewski, J. Am. Chem. Soc., 2013, 135, 4227-4230.

21 D. Cordella, A. Kermagoret, A. Debuigne, R. Riva, I. German, M. Isik, C. Jérôme, D. Mecerreyes, D. Taton and C. Detrembleur, ACS Macro Lett., 2014, 3, 1276-1280.

22 D. England, N. Tambe and J. Texter, ACS Macro Lett., 2012, 1, 310-314.

23 Q. Ye, T. Gao, F. Wan, B. Yu, X. Pei, F. Zhou and Q. Xue, J. Mater. Chem., 2012, 22, 13123-13131.

24 I. Abdelhedi-Miladi, D. Montarnal, M. M. Obadia, H. Ben Romdhane and E. Drockenmuller, ACS Macro Lett., 2014, 3, 1187-1190.

25 C. Barner-Kowollik, Handbook of RAFT Polymerization, Wiley-VCH, Weinheim, Germany, 2008.

26 Y. Li, G. Li, X. Wang, Z. Zhu, H. Ma, T. Zhang and J. Jin, Chem. Commun., 2012, 48, 8222-8224.

27 J. E. Bara, S. Lessmann, C. J. Gabriel, E. S. Hatakeyama, R. D. Noble and D. L. Gin, Ind. Eng. Chem. Res., 2007, 46, 5397-5404.

28 E. H. I. J. Brandrup and E. A. Grulke, Polymer Handbook, John Wiley and Sons, Weinheim, Germany, 1999.

29 R. Marcilla, J. A. Blazquez, R. Fernandez, H. Grande, J. A. Pomposo and D. Mecerreyes, Macromol. Chem. Phys, 2005, 206, 299-304.
30 A. S. Goldmann, M. Glassner, A. J. Inglis and C. BarnerKowollik, Macromol. Rapid Commun., 2013, 34, 810-849.

31 J. Fenn, M. Mann, C. Meng, S. Wong and C. Whitehouse, Science, 1989, 246, 64-71.

32 A. Calderaro, M.-C. Arcangeletti, I. Rodighiero, M. Buttrini, C. Gorrini, F. Motta, D. Germini, M.-C. Medici, C. Chezzi and F. De Conto, Sci. Rep., 2014, 4, 6803-6813.

33 P. A. Hunt, C. R. Ashworth and R. P. Matthews, Chem. Soc. Rev., 2015, 44, 1257-1288.

34 J. Pinaud, J. Vignolle, Y. Gnanou and D. Taton, Macromolecules, 2011, 44, 1900-1908.

35 M. C. Kroon, W. Buijs, C. J. Peters and G.-J. Witkamp, Thermochim. Acta, 2007, 465, 40-47.

36 H. C. M. Byrd and C. N. McEwen, Anal. Chem., 2000, 72, 4568-4576.

37 D. V. Zagorevskii, M. J. Nasrullah, V. Raghunadh and B. C. Benicewicz, Rapid Commun. Mass Spectrom., 2006, 20, 178-180.

38 M. Dietrich, M. Glassner, T. Gruendling, C. Schmid, J. Falkenhagen and C. Barner-Kowollik, Polym. Chem., 2010, 1, 634-644.

39 B. Yameen, C. Rodriguez-Emmenegger, C. M. Preuss, O. Pop-Georgievski, E. Verveniotis, V. Trouillet, B. Rezek and C. Barner-Kowollik, Chem. Commun., 2013, 49, 86238625.

40 M. Zamfir, C. Rodriguez-Emmenegger, S. Bauer, L. Barner, A. Rosenhahn and C. Barner-Kowollik, J. Mater. Chem. B, 2013, 1, 6027-6034.

41 C. M. Preuss, A. S. Goldmann, V. Trouillet, A. Walther and C. Barner-Kowollik, Macromol. Rapid Commun., 2013, 34, 640-644.

42 M. Kaupp, T. Tischer, A. F. Hirschbiel, A. P. Vogt, U. Geckle, V. Trouillet, T. Hofe, M. H. Stenzel and C. Barner-Kowollik, Macromolecules, 2013, 46, 6858-6872.

43 R. Gracia, K. Vijayakrishna and D. Mecerreyes, React. Funct. Polym., 2014, 79, 54-58.

44 Y.-J. Lu, W.-L. Wong and C.-F. Chow, Catal. Commun., 2015, 69, 25-28.

45 A. Herrmann, G. Mihov, G. W. M. Vandermeulen, H.-A. Klok and K. Müllen, Tetrahedron, 2003, 59, 3925-3935. 